\title{
PERANCANGAN SISTEM INFORMASI PELAYANAN WEDDING ORGANIZER BERBASIS DESKTOP PADA HOKEY HOKKY GALERI
}

\author{
Mega Fitriyana $^{1}$, Agus Riyanto $^{2}$, Lengsi Manurung ${ }^{3}$ \\ 1,2,3 Program Studi Informatika, FTIK, Universitas Indraprasta PGRI \\ Jalan Raya Tengah No 80, Kelurahan Gedong, Pasar Rebo, Jakarta Timur \\ 1megafitriyana26@gmail.com, ${ }^{2}$ rann4004@gmail.com, ${ }^{3}$ manurunglengsi@gmail.com
}

\begin{abstract}
ABSTRAK
Hokey Hokky Galeri merupakan suatu usaha yang dapat memberikan pelayanan jasa dalam mempersiapkan resepsi pernikahan. Hokey Hokky Galeri Wedding Organizer yang berada di Adiwerna, Tegal. Perusahaan ini dalam pengelolaan datanya masih menggunakan sistem konvensional, mulai dari pencatatan client yang menyewa wedding organizer, penyimpanan data yang berkaitan dengan proses transaksi sampai pembuatan laporan. Tujuan dari perancangan sistem ini adalah untuk merancang dan menerapkan suatu sistem informasi pelayanan wedding organizer yang dapat membantu dan mempermudah karyawan dan pemilik Hokey Hokky Galeri dalam melakukan pelayanan kepada pelanggan. Metodologi penelitian yang digunakan dalam sistem pengolahan data yaitu teknik pengumpulan data seperti observasi, studi lapangan yaitu dengan melakukan pengamatan secara langsung, serta melakukan penelitian kepustakaan berdasarkan referensi yang relevan dengan masalah sistem informasi pelayanan wedding organizer. Metode pengembangan sistem yang digunakan adalah metode software development life cycle model prototipe. Hasil dari penelitian ini adalah adanya suatu perancangan sistem informasi yang dibuat dengan bahasa pemrograman Java NetBeans dan penyimpanan data menggunakan database dari MySQL, sehingga dapat membantu dan mempermudah karyawan dan pemilik wedding organizer dalam melakukan proses pelayanan kepada pelanggan.
\end{abstract}

Kata Kunci: Sistem Informasi, Pelayanan Wedding Organizer, Desktop

\begin{abstract}
Hokey Hokky Gallery is a business that can provide services in preparing weddings. Hokey Hokky Gallery Wedding Organizer located in Adiwerna, Tegal. The company in data management still uses conventional systems, ranging from recording customers who hire wedding organizers, storing data related to the transaction process to making reports. The purpose of designing this system is to design and implement a wedding organizer service information system that can assist and facilitate employees and owners of Hokey Hokky Gallery in providing services to customers. The research methodology used in the data processing system is data collection techniques such as observation, field study, namely by making direct observations, and conducting library research based on references relevant to the problem of information system services of wedding organizers. The system development method used is the prototype software development life cycle model method. The result of this research is the design of information systems made with Java NetBeans programming language and data storage using a database of MySQL, so it can help and facilitate workers and owners of wedding organizers to perform the service process to customers.
\end{abstract}

Key Word: Information System, Wedding Organizer Service, Desktop

\section{PENDAHULUAN}

Pernikahan adalah bentuk hubungan paling sakral dan terpenting di antara manusia. Dengan cara ini, setiap pasangan akan membuat rencana pernikahan yang total dalam melaksanakan resepsi pernikahannya. Tentunya ini menjadi peluang bisnis bagi pemilik Wedding Organizer dalam sebuah penyelenggaraan acara pernikahan untuk membantu calon pengantin beserta keluarganya mengadakan rangkaian jamuan pernikahan sesuai dengan jadwal yang telah ditentukan. Wedding Organizer merupakan suatu usaha yang dapat memberikan pelayanan jasa dalam mempersiapkan resepsi pernikahan. Salah satunya pada Hokey Hokky Galeri Wedding Organizer merupakan perusahaan yang bergerak di bidang Wedding Organizer (WO). Hokey Hokky Galeri Wedding Organizer yang berlokasi di Jl. Manunggal, Gambyongan, Tembok Luwung, Kecamatan Adiwerna, Tegal, Jawa Tengah. Perusahaan ini menyediakan layanan jasa seperti berbagai macam paket pernikahan, paket akad, paket lamaran, penyewaan 
gedung, dekorasi pelaminan, pemandu acara, serta tata rias dan busana pengantin.

Dalam pengembangan perusahaan sampai saat ini terdapat kesulitan ketika mengelola pemesanan event atau paket pernikahan karena belum terkomputerisasi atau masih manual, mulai dari pencatatan client yang menyewa wedding organizer, penyimpanan data yang berkaitan dengan proses transaksi sampai pembuatan laporan. Hal ini tentu sangat beresiko bagi perusahaan dalam kehilangan data dan dapat terjadi kesalahan pendataan, kurang akuratnya laporan yang dibuat dan keterlambatan dalam pencarian data, karena masih menggunakan dokumen manual sehingga hal tersebut kurang efektif dan efisien. Adapun maksud dari pembuatan aplikasi berbasis desktop ini adalah membuat aplikasi yang memberikan dapat memberikan kemudahan bagi Hokey Hokky Galeri Wedding Organizer dalam mengelola pemesanan data acara pernikahan serta dalam pengelolaan laporan transaksi, sehingga dapat meminimalisir kesalahan pengolahan data.

Tujuan dari penelitian ini ialah untuk mempermudah serta mempercepat kinerja dalam pengolahan data dalam pemesanan paket pernikahan pada Hokey Hokky Galeri.

Sistem merupakan satu set elemen atau komponen yang terkait erat hubungan timbal balik, dimana bekerja sama untuk mencapai tujuan yang diinginkan. (Herliana \& Rasyid, 2016b)

Sistem dapat didefinisikan sebagai kumpulan elemen berupa data, jaringan program yang saling berhubungan, sumber daya manusia, teknologi, perangkat keras dan perangkat lunak, yang berinteraksi sebagai satu kesatuan untuk mencapai tujuan tertentu yang sama. (Maniah; Hamidin, 2017).

Informasi merupakan suatu hasil dari data yang diolah menjadi bentuk yang lebih berguna dan lebih berarti bagi penerimanya yang menggambarkan suatu kejadian yang nyata dan digunakan untuk pengambilan keputusan. (Herliana \& Rasyid, 2016a)

Informasi dapat didefinisikan sebagai pemrosesan input yang terorganisir, memiliki arti, dan berguna bagi penerimanya. (Wibawa, 2017)

Langkah pertama untuk membuat sistem adalah merancang sistem. Perancangan merupakan proses merumuskan spesifikasi baru berdasarkan rekomendasi hasil analisis sistem. (Nugroho, 2016)

Sistem informasi dapat diartikan sebagai sekumpulan unsur atau variable yang saling terorganisasi, saling berinteraksi dan membutuhkan satu sama lain agar saling bekerjasama sehingga memberikan manfaat bagi penerimanya. (Farell et al., 2018)

Pelayanan memiliki arti yang beragam dalam hal pekerjaan dan cara bekerja dari para juru layan yang ditujukan untuk memberikan kepuasan kepada pelanggan. (Wahab, 2017)

Wedding Organizer adalah suatu organisasi atau event organizer yang menawarkan berbagai macam paket pernikahan diantaranya tata rias dan busana, florist dan dekorasi, gedung, photography, video shooting dan lain-lain. (Nurpatonah, 2015)

Wedding organizer dapat diartikan layanan personal yang mengoperasikan karyanya dengan membantu calon pengantin dan keluarganya dalam menyelenggarakan acara pernikahannya dengan rangkaian pesta pernikahan sebagai scedule dan budget yang telah ditetapkan. (Fuad et al., 2018)

\section{METODE PENELITIAN}

Desain Penelitian

Desain penelitian yang digunakan penulis untuk melakukan penelitian adalah metode kualitatif. Penelitian kualitatif adalah penelitian yang cenderung menggunakan analisis. Proses dan makna lebih menonjol dalam penelitian kualitatif. Metode yang digunakan dalam penelitian ini adalah metode penelitian kualitatif bertujuan untuk memahami suatu obyek yang alamiah (natural) sehingga penelitian ini disebut penulisan naturalistic, agar dapat mengembangkan konsep sensitivitas pada masalah yang dihadapi, dan tidak dimanipulasi oleh peneliti. 
Metode Pengumpulan Data

Metode pengumpulan data adalah metode yang digunakan penulis untuk mengumpulkan data. Manfaat dari pengumpulan data yaitu memperoleh informasi yang dibutuhkan untuk mencapai tujuan penelitian. Berbagai macam metode pengumpulan data tersedia untuk penelitian. Metode pengumpulan data dapat digunakan sendiri atau kombinasi dari kedua metode. Berikut metode pengumpulan data yang digunakan penulis dalam menyusun penelitian antara lain:

\section{a. Wawancara}

Metode wawancara merupakan dialog antara dua pihak atau lebih yang memiliki tujuan tertentu. Wawancara termasuk salah metode pengumpulan data yang dilakukan melalui tanya jawab langsung antara penulis dan narasumber. Metode ini cenderung digunakan untuk menganalisis informasi yang diperlukan dalam penelitian.

\section{b. Metode Observasi}

Metode observasi dapat diartikan sebagai salah satu cara dari pengumpulan suatu data dengan meneliti, meninjau, mengamati secara langsung di tempat penelitian atau lapangan untuk lebih memahami kejadian yang terjadi, kemudian menggunakan catatan atau alat bantu lainnya dalam menulis hasil observasi. Observasi yang dilakukan peneliti dilakukan secara langsung di lapangan dengan mengamati sistem yang berjalan pada Hokey Hokky Galeri serta dapat melakukan pencatatan guna memenuhi kebutuhan penelitian.

c. Sumber Data Melalui website yang ada di internet

Sumber data merupakan sumber subjek dari mana data dapat diperoleh. Penulis mengunjungi beberapa website untuk mengumpulkan artikel dan kutipan yang berkaitan dengan penelitian ini.

\section{Langkah-Langkah Pengembangan Sistem}

Dalam membangun sebuah sistem informasi harus ada pengembangan atau peningkatan dari program yang sudah ada untuk menjadi lebih baik, serta terus mengikuti perkembangan zaman dan beradaptasi sesuai kebutuhan pengguna. Saat mengembangkan sistem, dibutuhkan metodelogi dalam penyusunan dan prosedur apa saja yang harus dilakukan terlebih dahulu. Metode pengembangan sistem menggunakan metode SDLC (Sistem Development Life Cycle) atau sering disebut sebagai pendekatan air terjun (waterfall). Berdasarkan penelitian ini penulis menggunakan pengembangan sistem Waterfall. Metode Waterfall memiliki arti model pengembangan aplikasi termasuk dalam siklus hidup klasik, menekankan urutan dan tahapan secara terstruktur atau tersusun. Seperti namanya metode Waterfall ini mirip dengan air terjun, dimana setiap bagian dijalankan secara berurutan dari atas ke bawah. Berikut alur pengembangan sistem dengan metode Waterfall:

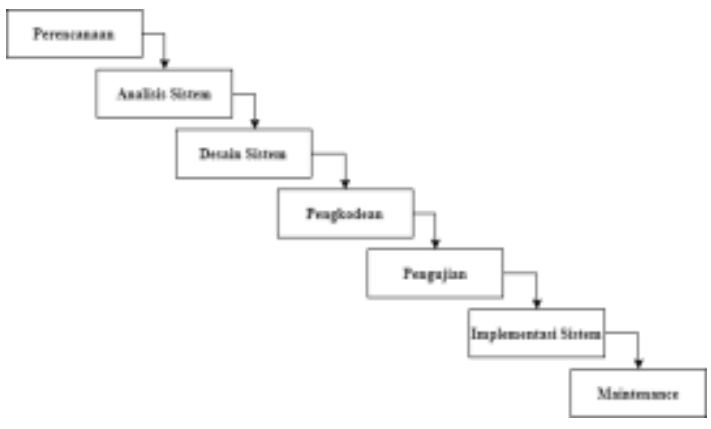

Gambar 1. Model Waterfall

\section{a. Planning (Perencanaan)}

Dalam tahap perencanaan ini dilakukan untuk melihat apa saja yang dibutuhkan pada projek. Proses ini meliputi menghitung tenaga kerja dan sumber daya material yang dibutuhkan, menetapkan jadwal dengan tujuan dan sasaran, dibentuknya tim dan struktur kepemimpinan dalam projek.

\section{b. Analisis Sistem}

Langkah kedua dari metode waterfall adalah merencanakan dan menganalisis kebutuhan perangkat lunak yang diselesaikan. Kebutuhan tersebut dapat dilihat dari hasil wawancara, survei dan observasi. Analisis dilakukan untuk mengetahui komponen apa saja pada sistem yang sedang berjalan, dapat berupa perangkat keras, perangkat lunak.

\section{c. Desain Sistem}

Pada tahap desain sistem ini, akan dibuat sketsa dari sistem secara keseluruhan dan agar dapat menentukan detail algoritma untuk alur software. Tahap desain membantu untuk menentukan persyaratan perangkat keras, sistem dan menentukan arsitektur sistem yang akan dibentuk secara keseluruhan. Desain 
sistem sangat dibutuhkan agar dapat memenuhi tujuan dari dibuat atau diciptakannya suatu sistem tersebut.

\section{d. Pengkodean}

Tahapan pengkodean ini merupakan penjabaran dari kode program sesuai dengan kebutuhan dalam menggunakan berbagai tools dan bahasa pemrograman seperti Java. Oleh karena itu, pada tahap ini akan lebih berpusat pada masalah teknis, dimana hasil uraian perancangan perangkat lunak akan diubah menggunakan bahasa pemrograman.

\section{e. Pengujian}

Tahap kelima memasuki proses pengujian, setelah melakukan proses pengkodean. Pada tahap pengujian ini, modul yang dibuat pada tahap sebelumnya akan dikombinasikan. Setelah proses sistem selesai dilakukan, langkah selanjutnya adalah pengujian modul. Tahap ini bertujuan untuk mengetahui apakah perangkat lunak memenuhi persyaratan desain dan apakah fungsi aplikasi berjalan dengan baik serta memeriksa apakah hasil dari pengembangan tersebut sesuai dengan apa yang diinginkan. Oleh karena itu pada tahap pengujian dapat mencegah segala kemungkinan terjadinya kesalahan sistem.

\section{f. Implementasi Sistem}

Implementasi sistem merupakan proses yang dilakukan untuk memasukkan sistem informasi yang baru ke dalam sistem yang lama. Pada tahap implementasi, perihal dan tujuan kerangka sistem harus dievaluasi kembali saat melakukan penerapan sistem dan alur kerja. Perangkat lunak dibuat sebagai program yang dapat langsung berhubungan dengan sistem operasi dan prasarana. Pada tahap ini pula sistem informasi sudah dapat digunakan oleh pengguna (brainware) setelah lulus tahap pengujian.

\section{g. Maintenance}

Setelah melakukan tahapan implementasi sistem lalu tahap terakhir dari metode waterfall adalah melakukan pengoperasian dan perbaikan aplikasi. Maintenance diperlukan guna menjaga setiap peralatan atau mesin yang digunakan dalam kegiatan pengoperasian aplikasi agar terhindar dari kerusakan.

\section{HASIL DAN PEMBAHASAN}

Berikut adalah gambaran dekomposisi Fungsi yang Diusulkan pada Hokey Hokky Galeri

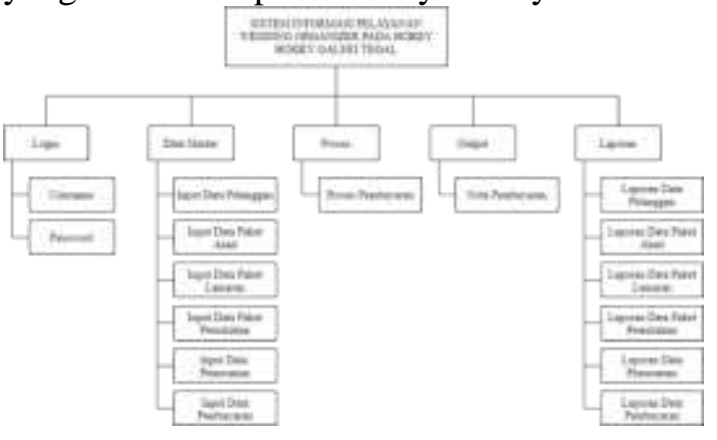

Gambar 2. Dekomposisi Fungsi yang Diusulkan

Adapun di bawah ini adalah tampilan layar login, beranda, data paket akad, data paket lamaran, data paket pernikahan, data pelanggan, data pemesanan, data pembayaran serta laporan yang yang ditampilkan dalam pengujian program adalah sebagai berikut:

\section{Tampilan Login}

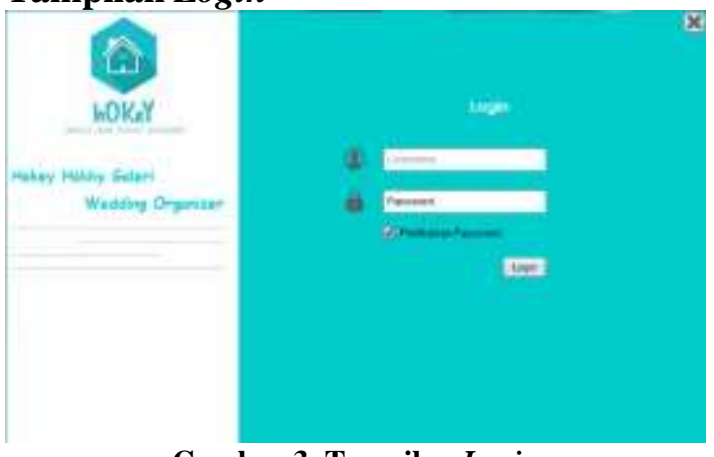

Pada tampilan layar login terdapat username dan password yang harus diisi terlebih dahulu oleh admin, lalu ada tombol button berfungsi untuk masuk kedalam tampilan layar aplikasi selanjutnya yaitu tampilan layar beranda.

\section{Tampilan Beranda}

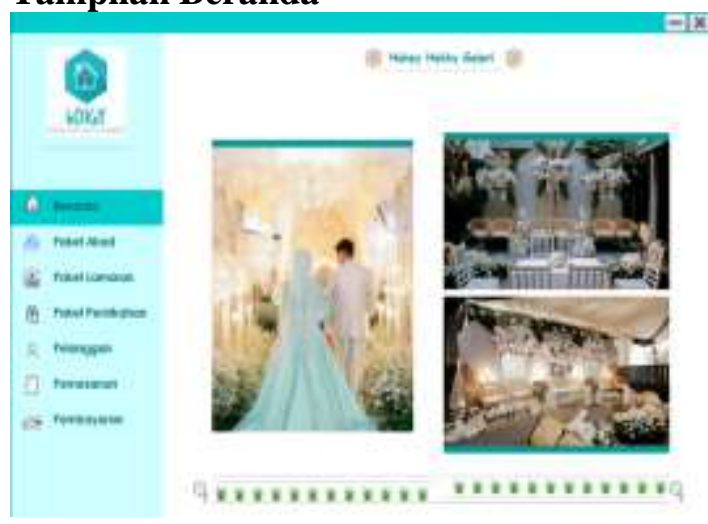

Gambar 4. Tampilan Beranda 
Pada tampilan layar beranda terdapat gambar kegiatan dalam acara pada Hokey Hokky Galeri. Beberapa gambar yang ditampilkan saat acara pernikahan, dekorasi pernikahan dan yang lainnya.

\section{Tampilan Data Paket Akad}

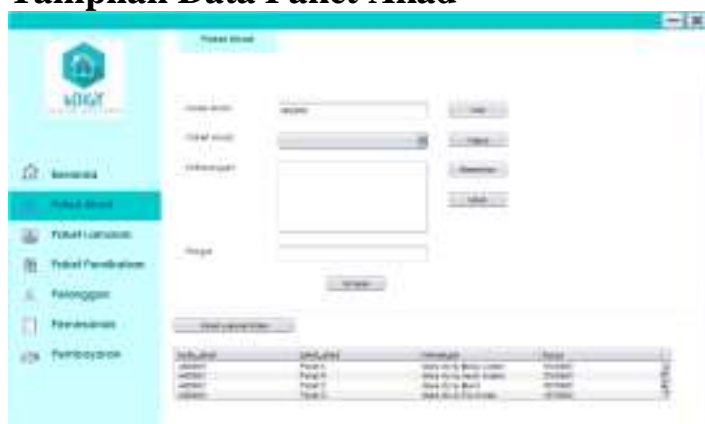

Gambar 5. Tampilan Data Paket Akad

Pada tampilan layar data paket akad terdapat kode akad, paket akad, keterangan dan harga yang harus diisi oleh admin sesuai dengan paket yang ada pada Hokey Hokky Galeri.

\section{Tampilan Data Paket Lamaran}

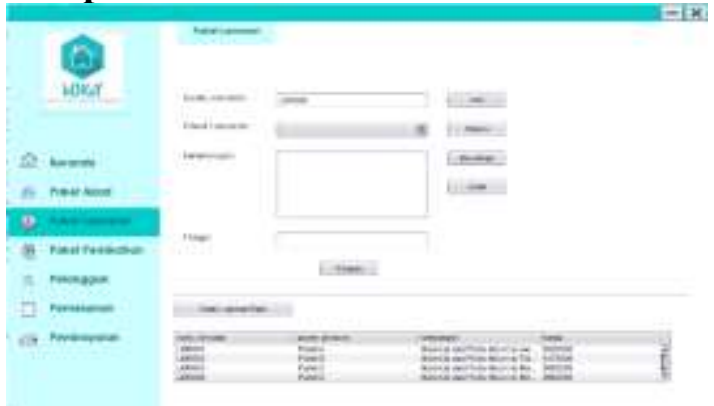

Gambar 6. Tampilan Data Paket Lamaran

Pada tampilan layar masukan data paket lamaran terdapat kode lamaran, paket lamaran, keterangan dan harga yang harus diisi oleh admin sesuai dengan paket yang ada pada Hokey Hokky Galeri.

\section{Tampilan Data Paket Pernikahan}

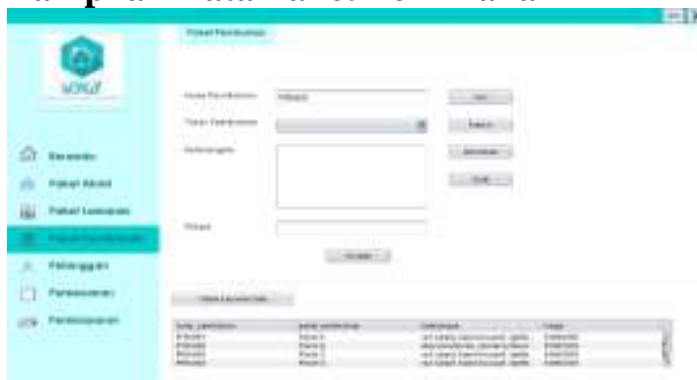

Gambar 7. Tampilan Data Paket Pernikahan

Pada tampilan layar masukan data paket pernikahan terdapat kode pernikahan, paket pernikahan, keterangan dan harga yang harus diisi oleh admin sesuai dengan paket yang ada pada Hokey Hokky Galeri.

\section{Tampilan Data Pelanggan}

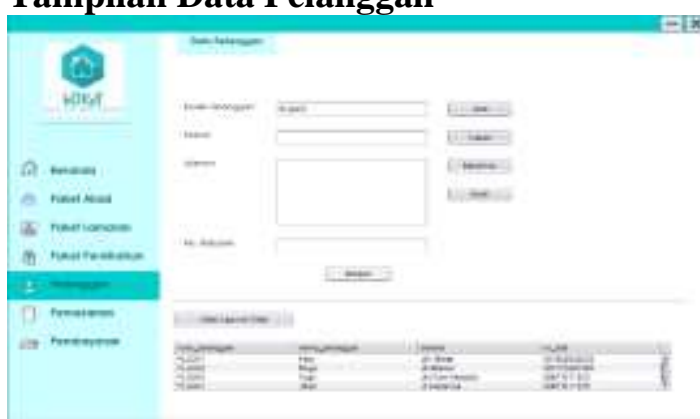

Gambar 8. Tampilan Data Pelanggan

Pada tampilan terdapat nama, alamat, nomor telepon yang harus diisi oleh admin.

\section{Tampilan Data Pemesanan}

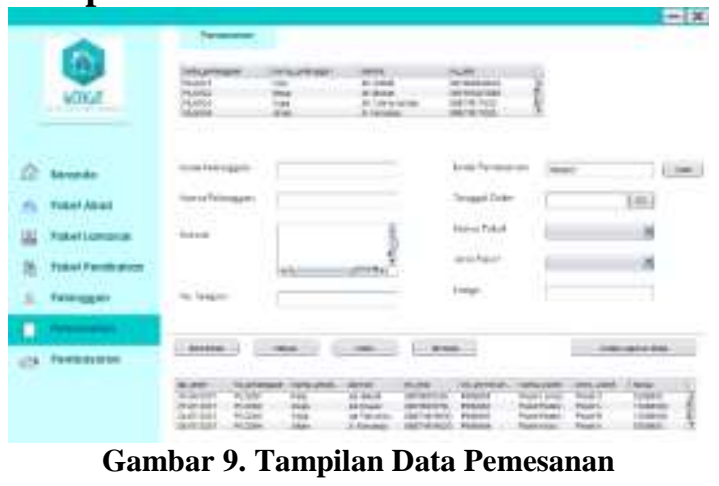

Pada tampilan data pemesanan terdapat kode pelanggan, nama pelanggan, alamat, nomor telepon, kode pemesanan, tanggal order, nama paket, jenis paket, dan harga sesuai dengan paket yang dipilih oleh pelanggan yang harus diisi oleh admin.

\section{Tampilan Data Pembayaran}

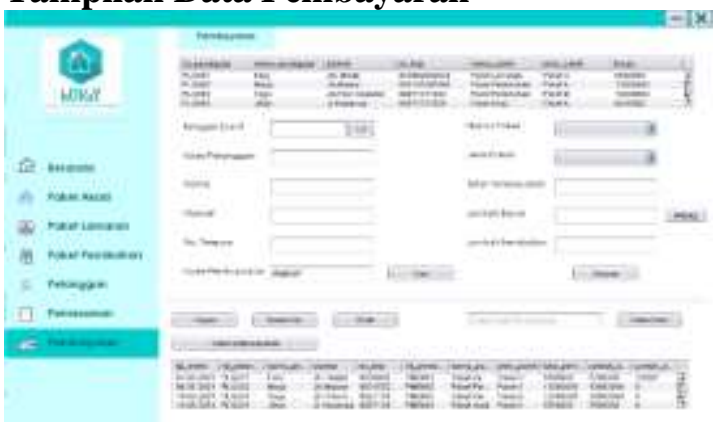

Gambar 10. Tampilan Data Pembayaran

Pada tampilan data pembayaran terdapat tanggal event, kode pelanggan, nama pelanggan, alamat, nomor telepon, kode pembayaran, nama paket, jenis paket, total 
pembayaran, jumlah bayar, dan jumlah kembalian sesuai dengan total pembayaran pelanggan yang harus diisi oleh admin.

\section{Tampilan Laporan Data Paket Akad}

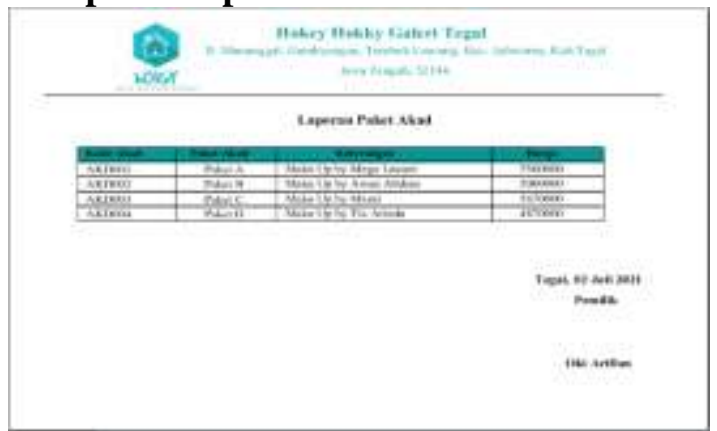

Gambar 11. Tampilan Laporan Data Paket Akad

Pada tampilan data paket akad menampilkan data paket akad yang telah tersimpan dan dicetak menghasilkan laporan data paket akad.

\section{Tampilan Laporan Data Paket Lamaran}

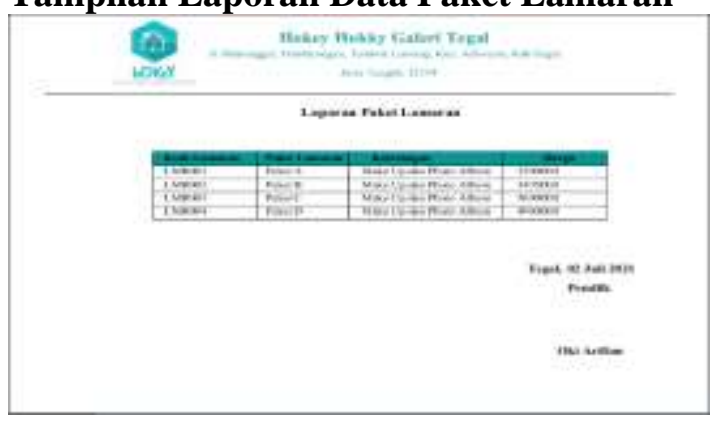

Gambar 12. Tampilan Laporan Data Paket Lamaran

Pada tampilan layar data paket lamaran menampilkan data paket lamaran yang telah tersimpan dan dicetak menghasilkan laporan data paket lamaran.

\section{Tampilan Laporan Data Paket Pernikahan}

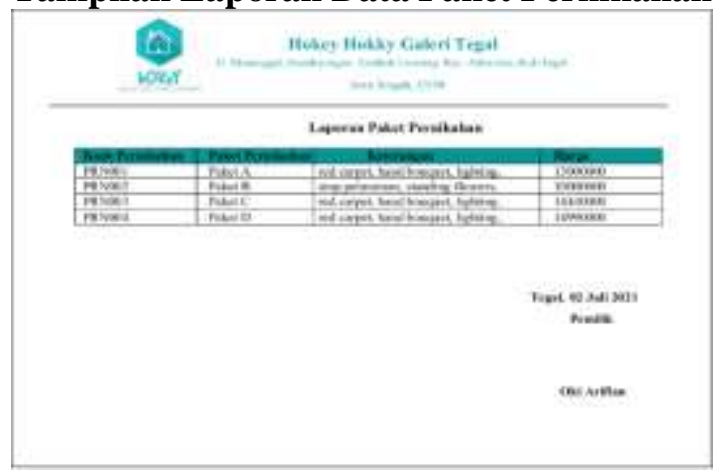

Gambar 13. Tampilan Laporan Data Paket Pernikahan

Pada tampilan data paket pernikahan menampilkan data paket pernikahan yang telah tersimpan dan dicetak menghasilkan laporan data paket pernikahan.

\section{Tampilan Laporan Data Pelanggan}

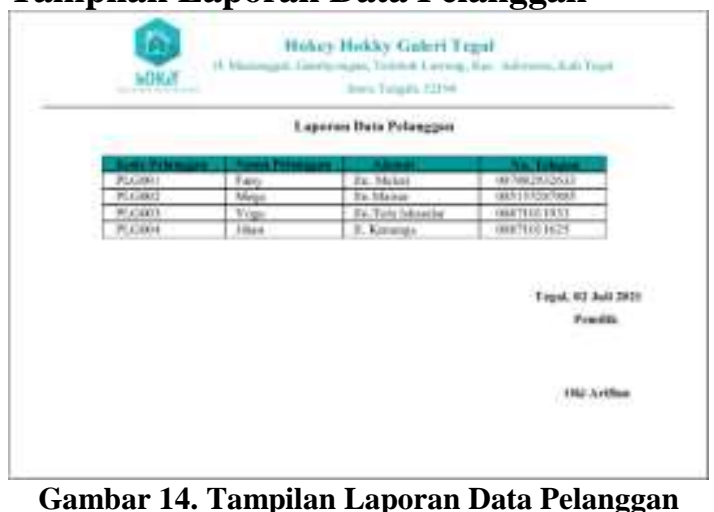

Pada tampilan data pelanggan menampilkan data pelanggan yang telah tersimpan dan dicetak menghasilkan laporan data pelanggan.

\section{Tampilan Laporan Data Pemesanan}

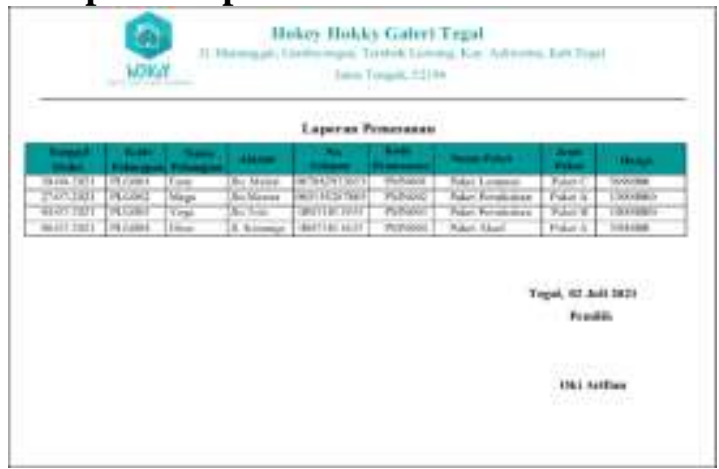

Gambar 15. Tampilan Laporan Data Pemesanan

Pada tampilan data pemesanan menampilkan data pemesanan yang telah tersimpan dan dicetak menghasilkan laporan data pemesanan.

\section{Tampilan Laporan Data Pembayaran}

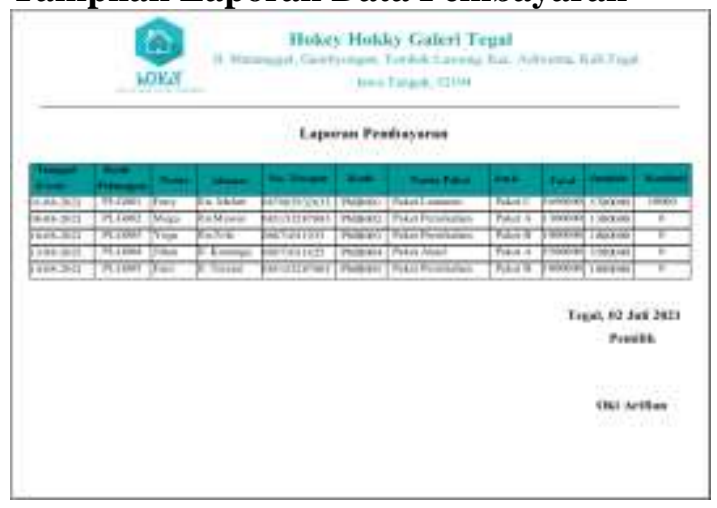

Gambar 16. Tampilan Laporan Data Pembayaran

Pada tampilan layar keluaran data pembayaran menampilkan data pembayaran 
yang telah tersimpan dan dicetak menghasilkan laporan data pembayaran.

\section{SIMPULAN DAN SARAN}

Dari hasil penelitian pada Hokey Hokky Galeri yang telah terlaksana terdapat beberapa simpulan yang telah dibuat, yaitu perancangan sistem informasi berbasis desktop dalam mendukung pelayanan pada Hokey Hokky Galeri memberikan kemudahan bagi pekerjaan staff administrasi, pemilik wedding organizer.

Mendukung dan memudahkan dalam pembuatan laporan pembayaran dan pemesanan data yang dibutuhkan dapat dicari lebih cepat tanpa harus menunggu lama Sistem ini dapat meminimalisir kesalahan yang dapat terjadi akibat kelalaian jika masih dijalankan secara konvensional terutama pada saat pengambilan data. Membantu Wedding Organizer pada Hokey Hokky Galeri untuk mengolah data terutama dalam pengolahan data dan pencarian data serta memberikan kemudahan dalam pembuatan laporan data paket akad, data paket lamaran, data paket pernikahan, data pelanggan, data pemesanan, dan data pembayaran.

Saran yang penulis kemukakan diharapkan dapat meningkatkan hasil yang lebih baik dari sistem yang dijalankan sekarang dapat ditemukan sistem yang lebih baik lagi.

\section{DAFTAR PUSTAKA}

Farell, G., Saputra, H. K., \& Novid, I. (2018). Rancang bangun sistem informasi pengarsipan surat menyurat (studi kasus fakultas teknik unp). Jurnal Teknologi Informasi Dan Pendidikan, 11(2), 5562.

Fuad, H., Budiman, A., \& Kurniasari, D. (2018). Perancangan Sistem Informasi Pemesanan Paket Pernikahan Berbasis Web Study Kasus Di Wedding Organizer PJ Management. Jurnal Sisfotek Global, 8(2).

Herliana, A., \& Rasyid, P. M. (2016a). Sistem Informasi Monitoring Pengembangan Software Pada Tahap. Jurnal Informatika, 1, 41-50.

Herliana, A., \& Rasyid, P. M. (2016b). Sistem Informasi monitoring pengembangan software pada tahap development berbasis web. Jurnal Informatika, 3(1).
Maniah; Hamidin, D. (2017). Analisis Dan Perancangan Sistem. Universitas Widya Mandala https://doi.org/10.1086/597550

Nugroho, F. E. (2016). Perancangan Sistem Informasi Penjualan Online Studi Kasus Tokoku. Simetris : Jurnal Teknik Mesin, Elektro Dan Ilmu Komputer, 7(2), 717. https://doi.org/10.24176/simet.v7i2.786

Nurpatonah, E. (2015). Sistem Informasi Pemesanan Wedding Organizer Berbasis Web Pada Java Exist Management. Skripsi. Bandung: Fakultas Teknik Dan Ilmu Komputer Universitas Komputer Indonesia, 3.

Wahab, W. (2017). Pengaruh Kualitas Pelayanan terhadap Kepuasan Nasabah Industri Perbankan Syariah di Kota Pekanbaru. Maqdis: Jurnal Kajian Ekonomi Islam, 2(1), 51-66.

Wibawa, J. C. (2017). Rancang Bangun Sitem Iinformasi Akademik (Studi Kasus: SMP IT Nurul Islam Tengaran). Infotronik, 2(2), 75-84. 